\title{
Usefulness of lactate dehydrogenase and its isoenzymes as indicators of lung damage or inflammation
}

\author{
M. Drent*, N.A.M. Cobben*, R.F. Henderson**, E.F.M. Wouters*, M. van Dieijen-Visser+
}

Usefulness of lactate dehydrogenase and its isoenzymes as indicators of lung damage or inflammation. M. Drent, N.A.M. Cobben, R.F. Henderson, E.F.M. Wouters, M. van DieijenVisser. CERS Journals Ltd 1996.

ABSTRACT: This review describes the usefulness of monitoring the activity level of lactate dehydrogenase (LDH) and its isoenzyme pattern as indicators of pathological conditions in the lungs, such as cell damage or inflammation.

Cytoplasmatic cellular enzymes, like LDH, in the extracellular space, although of no further metabolic function in this space, are still of benefit because they serve as indicators suggestive of disturbances of the cellular integrity induced by pathological conditions. Since LDH is an enzyme present in essentially all major organ systems, serum LDH activity is abnormal in a large number of disorders.

Although the increase in total serum LDH activity is rather nonspecific, it is proposed that measurement of LDH activity levels and its isoenzyme pattern in pleural effusion and, more recently, in bronchoalveolar lavage fluid may provide additional information about lung and pulmonary endothelial cell injury.

Eur Respir J., 1996, 9, 1736-1742.

\author{
Depts of ${ }^{*}$ Pulmonology and ${ }^{+}$Clinical \\ Chemistry, University Hospital Maastricht, \\ The Netherlands. ${ }^{* *}$ Inhalation Toxicology \\ Research institute, Lovelace Biomedical \\ and Environmental Research Institute, \\ Albuquerque, New Mexico,USA.
}

Correspondence: M. Drent, University Hospital of Maastricht, Dept of Pulmonology, P.O. Box 5800, 6202 AZ Maastricht, The Netherlands

Keywords: Bronchoalveolar lavage, lactate dehydrogenase, lactase dehydrogenase isoenzymes, lung, pleural effusion, pulmonary disease

Received: February 61996

Accepted for publication February 261996
Cellular enzymes in the extracelluar space, although of no further metabolic function in this space, are still of benefit because they serve as indicators suggestive of disturbances of the cellular integrity induced by pathological conditions. Lactate dehydrogenase (LDH) is a cytoplasmatic enzyme present in essentially all major organ systems. The extracellular appearance of $\mathrm{LDH}$ is used to detect cell damage or cell death [1-3]. Due to its extraordinarily widespread distribution in the body, serum LDH is abnormal in a host of disorders [3-9]. It is released into the peripheral blood after cell death caused by, e.g. ischaemia, excess heat or cold, starvation, dehydration, injury, exposure to bacterial toxins, after ingestion of certain drugs, and from chemical poisonings $[1,2]$. Therefore, the total serum LDH is a highly sensitive, but nonspecific test.

In order to optimize the diagnostic value, LDH isoenzymes can be measured [3]. Although the serum LDH isoenzyme activity pattern has a slightly better specificity, the clinical value is still rather low. In contrast, measurement of LDH and LDH isoenzymes in pleural fluid, and more importantly in bronchoalveolar lavage (BAL) fluid, is useful to determine lung tissue damage and pulmonary endothelial cell injury [10-14].

Cellular changes in BAL fluid (BALF) during acute inflammation include an influx of polymorphonuclear neutrophils (PMNs) and activation of alveolar macrophages (AMs) [15-18]. The neutrophil has been implicated as contributing to the lung injury incurred during an inflammatory response $[15,18]$. It has been suggested that the neutrophil influx plays a major role in increasing the permeability of the alveolar/capillary barrier and in producing cellular toxicity during the inflammatory response [18-20]. In line with this, it was indicated that the cytotoxicity of neutrophils was associated with, e.g. reperfusion injury and adult respiratory distress syndrome (ARDS) [5].

If cell lysis occurs, or cell membranes are damaged, cytoplasmic enzymes, such as LDH and glutathione reductase (GR), are released into the extracellular space [4]. The enzymatic activities found in the BALF provide important information concerning the degree of cytotoxicity present, measured by extracellular activities of cytoplasmatic enzymes, such as LDH, and the release of lysosomal enzymes [4]. Some increase in LDH is caused by transudation of serum, but in previous studies this has been a minor component of the increased LDH activity in BALF [21]. The LDH in BALF appeared to originate from lung cells, probably AMs or PMNs [22-24]. However, the exact cellular source of these enzymes is still unknown.

The usefulness of measurement of LDH activity and its isoenzymes in serum, but especially in BALF and pleural effusions as indicators of lung damage or inflammation is reviewed.

\section{Biochemistry and physiology of LDH}

Lactate dehydrogenase (LDH, EC 1.1.1.27) is a hydrogen transfer enzyme that catalyses the oxidation of L-lactate to pyruvate with nicotinamide-adenine dinucleotide (NAD) ${ }^{+}$as hydrogen acceptor, the final step in the metabolic chain of anaerobic glycolysis. The reaction is reversible and the reaction equilibrium strongly favours the reverse reaction, namely the reduction of pyruvate (P) to lactate $(\mathrm{L})[1,2,25]$ : 


$$
\begin{aligned}
& \text { LDH, pH 8.8-9.8 } \\
& \text { L-lactate }+\mathrm{NAD}^{+} \quad \Leftrightarrow \quad \text { Pyruvate }+\mathrm{NADH}+\mathrm{H}^{+} \\
& \mathrm{pH} \text { 7.4-7.8 }
\end{aligned}
$$

A multiplicity of procedures for measurement of LDH activity have been developed over the last $25 \mathrm{yrs}$; the procedures use the forward $(\mathrm{L} \rightarrow \mathrm{P})$ and the reverse $(\mathrm{P} \rightarrow \mathrm{L})$ in almost equal numbers. The $\mathrm{L} \rightarrow \mathrm{P}$ assay has the following advantages: substrate inhibition by lactate is less than that produced by pyruvate; and the reaction linearity is more prolonged than that of the $\mathrm{P} \rightarrow \mathrm{L}$ assay. Advantages of the $\mathrm{P} \rightarrow \mathrm{L}$ assay are: a less expensive assay formulation (because of the much lower concentration of the reactants); the greater absorbency with time (thus allowing more precise measurements); and greater stability of the working reagents once they are prepared as assay solutions.

The enzyme is composed of four peptide chains of two types: $\mathrm{M}$ and $\mathrm{H}$, each under separate genetic control. Heart $(\mathrm{H})$ subunit or muscle $(\mathrm{M})$ subunit are so named because of their predominance in the respective tissues. In this way, five different isoenzymes, having different chemical and physical properties can be found. The isoenzymes all catalyse the same biochemical reaction but differ in their molecular structure, and are more or less organ specific $[1,2]$. Therefore, isoenzyme patterns can be used to localize the source of $\mathrm{LDH}$ release. The isoenzymes differ in reactivity to substrates, sensitivity to inhibitors, resistance to heat inactivation, cold lability, and electrophoretic mobility in tertiary structure and charge. Therefore, isoenzymes are separable electrophoretically. The subunit compositions of the five isoenzymes in order of decreasing anodal mobility in an alkaline medium are: LDH-1 (HHHH; $\left.\mathrm{H}_{4}\right)$; LDH-2 (HHHM; $\left.\mathrm{H}_{3} \mathrm{M}\right)$; LDH-3 (HHMM; $\left.\mathrm{H}_{2} \mathrm{M}_{2}\right)$; LDH-4 (HMMM; $\left.\mathrm{HM}_{3}\right)$; and LDH-5 $\left(\mathrm{MMMM} ; \mathrm{M}_{4}\right)[1,2]$.

Using the assay at $37^{\circ} \mathrm{C}$ by an enzymatic rate method, with pyruvate as a substrate, the reference ranges for $\mathrm{LDH}$ activity are $200-450 \mathrm{U} \cdot \mathrm{L}^{-1}$ in serum [25], and $10-50 \mathrm{U} \cdot \mathrm{L}^{-1}$ in BALF. The reference ranges in serum for $\mathrm{LDH}$ isoenzymes are: LDH-1 19-30\%; LDH-2 32-48\%; LDH-3 12-22\%; LDH-4 5-11\%; and LDH-5 5-13\%, [25]. Moreover, in BALF, reliable determination of LDH isoenzymes is only possible when the total LDH level in BALF is higher than $50 \mathrm{U} \cdot \mathrm{L}^{-1}$.

\section{Tissue activities of $\mathrm{LDH}$ and its isoenzymes}

Activity of LDH is present in almost all cells of the body and is found only in the cytoplasm of the cell $[1,2]$. The activities of isoenzymes are present in brain, kidney, liver, lung, lymph nodes, myocardium, skeletal muscle, spleen, erythrocytes, leucocytes, and also platelets $[1,2]$. Enzyme levels in various tissues (in $\mathrm{U} \cdot \mathrm{g}^{-1}$ wet weight) are very high compared to those in serum: liver 9,000; heart 25,000; kidney 15,000; skeletal muscle 9,000; lung 9,500 [2]. Thus, tissue levels are about 500 fold higher than those normally found in serum, and leakage of the enzyme from even a small mass of damaged tissue can increase the observed serum level of LDH to a significant extent. In addition to their higher enzyme concentration, many of these tissues show a different isoenzyme composition. In cardiac muscle, erythrocytes and kidney, the electrophoretically faster moving isoenzymes LDH1 and LDH-2 predominate. In liver and skeletal muscle, the more cathodal LDH-4 and LDH-5 isoenzymes predominate. Isoenzymes of intermediate mobility account for the LDH of many tissues. Specific percentages of isoenzymes for the lung are estimated: LDH-1, 10\%; LDH2, 20\%; LDH-3, 30\%; LDH-4, 25\%; and LDH-5, $15 \%$ [1].

Elevation of total LDH activity in lung tissue was found several days after exposure of rodents to high or low levels of $\mathrm{O}_{2}$, to cadmium aerosols, or to $\mathrm{NO}_{2}$ [26-29]. However, these studies did not distinguish between LDH of lung tissue and of infiltrating cells. In a study using histochemical staining techniques, a viral pulmonary infection in mice resulted in a decreased LDH activity in lung cells after 6 days. In unexposed mice, LDH activity was highest in the bronchial and type II alveolar epithelial cells lining the airways [29]. Thus, there seems to be a time-related effect; and, therefore, knowing the moment that the LDH activity was measured is of vital importance in interpreting the results of the analysis. Similarly, in extrinsic allergic alveolitis, the BALF profile was also recently found to be highly dependent on the time-point at which the material was obtained in relation to the last exposure to the causative antigen [30].

HENDERSON and co-workers [31] found a predominantly interstitial reaction rather than an exudative one, with mononuclear phagocytes and lymphocytes rather than PMNs being the predominant inflammatory cell types after inhalation of toxicants inducing pulmonary injury in hamsters. The elevated LDH tissue levels remained for more than 3 weeks after exposure, suggesting some residual subacute inflammation. Airway enzymatic and cytological responses were shown to be potentially useful as indicators of lung damage in toxicological screening, as well as screening of lung injury of unknown origin $[18,22,31,32]$.

\section{Serum LDH in pulmonary disease}

Lung-related disorders as possible sources of serum LDH abnormalities have been underreported, and isoenzyme patterns are seldom measured. A summary of several pulmonary disorders associated with elevated serum LDH levels in human is given in table 1. These disorders all have in common that cell damage or inflammation or both are involved in the pathogenesis [9-11, 3239]. In contrast, mostly in lung cancer - in the absence of liver metastases - no increased serum or BALF LDH was found (unpublished data). This suggests that no derangement of the alveolar/capillar barrier is involved in lung cancer.

An increase in airway LDH activity might arise from diverse sources, including: 1) rupture (necrosis) of airway and/or alveolar epithelial cells, AMs, or other pulmonary cell types; 2) increased flux of plasma derived LDH through an air/blood barrier rendered more permeable by pulmonary injury (e.g. oedema, haemorrhage); and 3) elevated plasma LDH concentration resulting in an increased plasma/alveolus concentration gradient, with consequent increased rate of passage of LDH across the air/blood barrier of a normal lung [13]. Studies have 
Table 1. - Pulmonary diseases associated with increased serum LDH activity

\begin{tabular}{lc}
\hline Pulmonary disorder & Main pathogenetic process \\
\hline Obstructive and other diseases & Cell damage or cell death \\
Emphysema & \\
Chronic obstructive pulmonary disease (COPD) & \\
Pneumothorax & \\
Pulmonary embolism & Inflammation \\
Microbial pulmonary disease & \\
Bronchopneumonia & \\
Tuberculosis & \\
Pneumocystis carinii pneumonia (PCP) & \\
Acquired immune deficiency syndrome (AIDS) & Inflammation and/or cell \\
Intersitial lung diseases & damage, remodelling/ fibrosis \\
Desquamative intersitial pneumonitis (DIP) & \\
Idiopathic pulmonary fibrosis (IPF) & \\
Hypersensitivity pneumonitis (HP) & \\
or extrinsic allergic alveolitis (EAA) & \\
Drug-induced pneumonitis & \\
Pulmonary alveolar proteinosis (PAP) & \\
Pneumoconiosis, silicosis pulmonum & \\
Acute respiratory distress syndrome (ARDS) & \\
Acute respiratory insufficiency &
\end{tabular}

suggested that the pulmonary interstitium can be seen as a significant part of the blood-lymph barrier when looking at protein transport. Lung parenchymal cells, or local inflammatory cells including AMs and PMNs, may be a potential source of elevation of serum $\mathrm{LDH}$ associated with pulmonary diseases. In vitro studies have demonstrated LDH leakage from type II pneumocytes, pulmonary endothelium and AMs following cellular damage caused by various stimuli. Injury to the basolateral aspect of endothelial cells would be expected to release LDH into the alveolar interstitium, and a compromised alveolar epithelial barrier would allow access of the enzyme into alveolar spaces. Mechanisms for increased levels of enzymes in the lavage fluid are usually considered to reflect cell damage, increased production and release from cells, and impaired catabolism [1]. Thus, LDH might be released from injured cells of the lung into the pulmonary interstitium and alveoli, or from damaged inflammatory cells that infiltrate the lung after treatment [14].

Only a few human studies have been carried out. DEREMEE [37] reported elevated serum LDH activity in five cases of interstitial pneumonitis, suggesting that $\mathrm{LDH}$ would be helpful in differentiating interstitial pneumonitis from sarcoidosis. More recently, Matusiewicz et al. [10] reported serum LDH to be a simple though nonspecific test, which appears to reflect changes of disease activity in patients with cryptogenic fibrosing alveolitis (CFA) and extrinsic allergic alveolitis or hypersensitivity pneumonitis, but not sarcoidosis. Moreover, in CFA an increasing percentage of BALF PMNs correlated with serum LDH levels, whereas in sarcoidosis the percentage of BALF lymphocytes correlated with serum LDH, suggesting different sources of the LDH activity [10].

Determination of the LDH isoenzymes might be of additional value to establish the origin of the elevated LDH activity. Moreover, alkaline phosphatase (AP) activity has been observed histochemically in type II pneumocytes $[22,23,40]$, which have been shown to proliferate following exposure to a pulmonary toxicant and to replace the damaged type I pneumocytes [41]. Therefore, increases in AP levels in BALF were noted as a marker of type II cell damage and/or proliferation [5, 22]. It is well-known that the type II pneumocyte is important in the repair of alveolar epithelium after injury and responds to oxidant stress (such as hyperoxia). It was suggested that adaptive responses to oxidant injury occur in type II pneumocytes after exposure to minerals. Future studies are needed to clarify the possible relationship between the LDH and AP activity and outcome in patients suffering from pulmonary diseases, as well as the role in the follow-up regarding prognosis and evaluation of medical treatment.

\section{Serum LDH isoenzyme patterns in pulmonary disease}

The isomorphic pattern of LDH isoenzymes in serum - showing LDH-2 levels greater than LDH-1 levels, with relatively lower levels of LDH-3, LDH-4 and LDH-5 - is common. In addition, diagnostically more specific patterns are identified. Several studies have shown the diagnostic use of the measurement of LDH activity in pulmonary diseases. However, the further role of LDH isoenzymes has not been extensively explored. The lung pattern is characterized by proportional increases in isoenzymes 3 , 4 and 5, compared to the isoenzyme patterns in normal serum $[9,42]$. It has been suggested that increased plasma LDH-3 activity reflects acute lung injury causing cell damage and cell death, as LDH-3 was to be found elevated in the plasma when pulmonary embolism occurred $[9,42]$. On occasions, a raised LDH level may be the only evidence to suggest the presence of a hidden embolus. The serum LDH-3 level is probably elevated because of the massive destruction of platelets after the formation of an embolus. Additionally, it is proposed that plasma LDH-3 isoenzymes are released into the circulation from injured alveolar capillary endothelial cells.

Therefore, LDH-3 may be a useful biochemical index of acute immunological antibody-mediated lung injury, 
with potential diagnostic and prognostic value in pulmonary disease [9]. Release of LDH-3 activity from injured pulmonary parenchyma into the circulation presumably produces the observed rise in plasma LDH-3 activity. However, during acute rejection of a pulmonary graft in man, serum LDH-4 and LDH-5 increased [43]. BANSAL and KAW [6] found that AMs contained all five LDH isoenzymes, LDH-5 being the most prominent. Despite the reported predominance of certain LDH isoenzymes related to particular pulmonary disorders, fractionation of serum LDH often revealed the isomorphic, i.e. normal serum pattern, whereas fractionation of pleural effusion or BALF showed a more specific increase in LDH isoenzyme fractions. To clarify the discrepancy between these isoenzyme patterns, it is important to compare the ratio of each isoenzyme/albumin in the respective fluid to the corresponding ratio in serum.

Some of the unusual LDH isoenzymes, such as LDH6 , may have diagnostic importance, however, the majority are laboratory curiosities. The presence of LDH-6 in serum carries a very poor prognosis, all earlier reported cases were critically ill. KeTCHUM et al. [44] described nine patients with LDH-6, of whom eight died during their hospital stay. In another study of 18 patients who showed the LDH- 6 band, 15 died. However, no common cause was apparent for the LDH-6. At the time that LDH6 was observed in the serum, all patients had hypotension and the great majority had documented episodes of hypoxaemia just preceding the LDH isoenzyme assay [44-47].

\section{LDH in BALF}

Although serum LDH, serum AP and serum protein cannot be used as indices of pulmonary disease, measurement of these parameters in BALF is a more specific alternative. LDH, known as a cytoplasmatic enzyme, occurs extracellularly in BALF only in the presence of damaged cells $[23,31]$. Therefore, analysis of BALF LDH is a potentially useful tool for evaluating lung tissue damage. Cellular as well as noncellular constituents have been extensively studied. The analysis of soluble components in BALF, along with the cellular components, has been used to rank the toxicity of respirable toxicants in the lung, and to determine the level of exposure to such toxicants that is required to produce a detectable inflammatory response in the lung $[4,7,14]$.

Some of the most commonly analysed soluble components of BALF are total protein (or albumin) concentrations, and the activity of enzymes, such as LDH, AP, and acid hydrolytic enzymes, such as $\beta$-glucuronidase. There are measurable levels of these components in BALF from nontreated animals [7]; increases in background levels can be used as a measure of the degree of the inflammatory response and, in some instances, are associated with a particular type of toxicant (table 2) [4]. In general, however, the changes observed are not toxicant-specific, but indicate the degree of the inflammatory response to any respirable toxicant. The parameters are also useful in determining the response of the lung to systemic toxicants that are known to damage the lung [13].

In several experiments, LDH, AP and protein were used as biochemical indices of pulmonary damage in
Table 2. - Most sensitive changes in bronchoalveolar lavage fluid (BALF) in response to different types of pollutants

\begin{tabular}{ll}
\hline Pollutant & Components of BALF increased \\
\hline Oxidant gases $\left(\mathrm{NO}_{2}, \mathrm{O}_{3}\right)$ & Neutrophils \\
Soluble metal salts & Protein \\
& Neutrophils \\
& Protein \\
Insoluble toxic particles, & Lactate dehydrogenase \\
including metal salts & Neutrophils \\
& Protein \\
& Lactate dehydrogenase \\
& Acid hydrolytic enzymes \\
\hline
\end{tabular}

(Modified from Henderson and Muggenburg [4]).

BALF, e.g. in rat models, they were found to be correlated with the degree of inflammatory cell influx in BALF from lungs exposured to pathogenic particulates $[4,22$, 32] (table 2).

Lysosomal enzyme activities, such as $\beta$-glucoronidase (BG), N-acetylglucosaminidase, or acid proteinase activities, provide a measure of macrophage activation or lysis $[4,5]$. AP activity in BALF has been associated with increased secretory activity of alveolar type II cells, or injury of these cells [22-24]. Other mediators of inflammatory response, such as tumour necrosis factor, various arachidonase metabolites, proteases and antiproteases, and interleukins may also be of help $[4,18,19]$. However, for screening, the analysis of BALF can be limited to a relatively small number of parameters. The total and differential cell counts, LDH, AP, and perhaps one lysosomal enzyme activity, along with the protein content of the BALF, are sufficient to measure the degree of the inflammatory response [4].

Changes in serum LDH do not reflect changes in lavage LDH [11]. However, looking at lavage LDH and its isoenzymes may be extremely helpful in elucidating pathogenic mechanisms in diffuse pulmonary diseases. Although total lavage LDH activity represents only about $0.1 \%$ of the total LDH activity available in lung tissue, the histological changes suggest that the lungs are a likely contributor to the increase in LDH activity observed in cell-free BALF in rats with induced lung injury [7].

SмIтн et al. [33] noted markedly increased total BALF LDH levels in Pneumocystis carinii pneumonia patients which were independent of BALF cell populations. The latter group also found that the BALF $\mathrm{LDH} /$ albumin ratio was significantly higher than the same ratio in serum [33]. This observation suggests that the lavage fluid LDH originates from pulmonary tissue, rather than reflecting transudation from blood to alveoli.

In the rat model, induced injury to the basolateral aspect of endothelial cells would be expected to release LDH into the alveolar interstitium, and a compromised alveolar epithelial barrier would allow access of the enzyme into alveolar spaces. Schultze et al. [14] suggested that the increased LDH activity in cell-free BALF found after experimentally-induced lung injury arises from lung tissue. Henderson and co-workers [31] also suggested that the source of LDH in BALF was most likely damaged lung cells. Thus, it appears that the increased serum LDH in several pulmonary disorders associated with inflammation and cell damage originates from the lung interstitium and flows back across a more permeable alveolocapillary 
membrane. Thereafter, the serum LDH level increases, as has been reported, e.g. in Pneumocystis carinii pneumonia [33-35], pulmonary alveolar proteinosis [11], desquamative interstitial pneumonitis [10,37-39], and extrinsic allergic alveolitis [10] (table 1). An analogous situation is seen in sarcoidosis - characterized by the formation of noncaseating epitheloid cell granulomas, probably antigen driven - where increased amounts of immunoglobulin $\mathrm{G}(\mathrm{IgG})$ produced at pulmonary sites of disease activity are considered responsible for the observed serum hypergammaglobulinaemia [48].

\section{LDH isoenzymes in BALF}

When homogenates of human pulmonary tissue were assayed for LDH, a particular and identifying isoenzyme pattern was found. Analysis of lung washing as a probe to detect early responses of the lung has used LDH activity in the airways of rats to detect the effect of a toxicant in the lung. Moreover, in animal studies, LDH isoenzyme patterns have been used to differentiate between various types of pulmonary injury and have helped to identify the sites of injury at a cellular level [49].

Analyses of the relative ratios of LDH isoenzymes in BALF and serum indicate that cationic isoenzymes 3, 4 and 5, are preferentially retained in the air spaces. Thus, despite increased permeability, it has been suggested that the alveolocapillary membrane continues to function as a sieving membrane, discriminating between proteins of equal molecular weight on the basis of electrical charge. Selective backflow of elevated BALF LDH, in particular isoenzyme 2 to the serum, may be responsible for the isomorphic LDH pattern seen in the serum of patients with Pneumocystis carinii pneumonia. In pulmonary alveolar proteinosis, there are a number of cells capable of releasing LDH into the alveolar space, including type I and type II alveolar epithelial cells, AMs, and even bronchiolar epithelial cells. HoFFMAN and Rogers [11] found an isomorphic isoenzyme pattern in serum of pulmonary alveolar proteinosis patients. This was in marked contrast to the $\mathrm{LDH}$ isoenzyme pattern observed in the lavage effluent, which showed a lower percentage of LDH-1 and LDH-2 and a higher percentage of LDH-3, LDH-4 and LDH-5. Moreover, the LDH elevation found consistently in the alveolar fluid points to this as the source of the serum LDH. The large quantities of $\mathrm{LDH}$ found in BALF and the isoenzyme pattern of the lavage LDH suggest that pulmonary cell death occurs to a considerable extent in pulmonary alveolar proteinosis.

SChultze et al. [14] reported that an intravenous injection of a small dose of monocrotaline pyrrole (MCTP), a putative, toxic metabolite of monocrotaline, causes injury of lung tissue, but not of other organs. Reported changes in LDH activity in cell-free BALF were characterized by increases in the isoenzymes LDH- 4 and LDH-5 and an elevated LDH-4/LDH-5 ratio in BALF only. The induced changes in the LDH isoenzyme pattern suggest that the increased LDH activity of cell-free BALF arises from lung tissue. Inflammatory cells in the lungs (such as AMs and PMNs) and leakage of plasma into the interstitium and alveolar spaces may slightly contribute to the increase of cell-free BALF LDH activity, in particular to the activity of LDH-5. However, these sources alone cannot explain the alterations in LDHisoenzyme patterns that occur in cell-free BALF after treatment of rats with MCTP [14].

\section{LDH and its isoenzymes in pleural effusion}

LDH activity has been extensively used in the analysis of pleural effusion, especially in distinguishing between transudate and exudate, and also between malignant and nonmalignant effusions [50-57]. However, few studies reporting the analysis of $\mathrm{LDH}$ isoenzymes in pleural effusion were found. The first results of studies of the diagnostic value of pleural fluid LDH-isoenzyme patterns have been conflicting. RICHTERICH and BURGER [58] reported that the LDH isoenzyme pattern of benign effusions reflected the serum pattern, whereas malignant effusions contained more LDH-4 and LDH-5. In contrast, others [57] have reported that malignant effusions were characterized by maximal enzyme activity in LDH-2, LDH-3 and $\mathrm{LDH}-4$, whereas benign effusions were characterized by maximal enzyme activity of LDH-4 and LDH-5.

A study of pleural fluid of 122 patients at the Johns Hopkins Hospital in 1971 showed the following results [54]. In general, transudative pleural effusion - having a total LDH lower than $200 \mathrm{U} \cdot \mathrm{L}^{-1}$ or $60 \%$ of the serum value - showed a slightly higher percentage of LDH-4 and LDH-5 compared to the serum values.

Studies of the exudative effusions showed that some malignant effusions had an LDH isoenzyme pattern different from that of the benign exudates. The fraction of LDH-2 was unusually high in approximately one third of the malignant exudative effusions, with a corresponding reduction in the LDH-4 and LDH-5 fractions. No relationship was found between the histological pattern of the malignancy and the pleural fluid isoenzyme pattern. Moreover, no significant differences were found in the pleural fluid LDH isoenzyme patterns between the various groups of benign exudative effusions [54].

VERGNON et al. [59] found an increase in LDH-5 isoenzyme level to be a good marker of malignant pleural effusion, except when the pleura is involved by malignant lymphoma or small cell lung carcinoma. The latter group [59] further concluded that the follow-up of the LDH-5 isoenzyme level in pleural fluid appears to be an accurate marker of the evolution of malignant pleural effusion. DEv et al. [60] found a significant difference in total LDH, LDH pleural fluid/serum ratio and LDH isoenzymes; minimum in cardiac failure and maximum in empyema. The value was intermediate in malignancy and other exudative conditions. The LDH-5 isoenzyme activity ratio between pleural fluid and serum tended to be higher in pleural effusions of mesothelioma origin than in those from nonmesothelial tumours.

In conclusion, comparison of LDH electrophoretic patterns found in serum and pleural fluid, is a valuable tool in the diagnostic work-up of pleural effusions, especially in the differentiation between malignant and nonmalignant origin of the pleural fluid.

In conclusion, $\mathrm{LDH}$, a cytoplasmatic enzyme, present in essentially all organ systems is thought to be released only after cell death. Various cell types are frequently characterized by different LDH isoenzyme profiles. Therefore, $\mathrm{LDH}$ isoenzyme activity patterns can be used to 
localize the cellular injury. In BALF, LDH activity and its isoenzyme pattern give a direct indication of pulmonary cell damage. However, future research should focus on the specific pulmonary cells that contribute to the local LDH increase, and the impact of intra-alveolar LDH on serum LDH. The screening of BALF by relatively simple, well-established biochemical assays has proved to be useful as an indicator of the lack of lung injury and of value in damage evaluation, especially in animal studies. Further studies are required to define the limits of usefulness of BALF screening for detecting acute inflammatory responses in the lung, and to assess the link between the LDH activity and the severity and prognosis of pulmonary diseases.

Furthermore, it will be necessary to determine whether the alterations in the lactate dehydrogenase isoenzyme composition in pleural effusion and BALF, observed in earlier studies, are restricted to particular lung diseases or whether they represent a more general pattern of lactate dehydrogenase isoenzyme profile abnormalities.

\section{References}

1. Lott JA, Nemensanszky E. Lactate dehydrogenase. In: Lott JA, Wolf PL, eds. Clinical Enzymology, a Caseoriented Approach. 1987; pp. 213-244.

2. Moss DW, Henderson AR. Enzymes. In: Burtis CA, Ashwood ER, eds. Tietz Textbook of Clinical Chemistry. 2nd edn. Philadelphia, Saunders Co., 1986; pp. 735-896.

3. Glick JH. Serum lactate dehydrogenase isoenzyme and total lactate dehydrogenase values in health and disease, and clincal evaluation of these test by means of discriminant analysis. Am J Clin Pathol 1969; 52: 320-328.

4. Henderson RF, Muggenburg BA. Bronchoalveolar lavage in animals. In: Baughman RB, ed. Bronchoalveolar Lavage. St Louis, Mosby Year Book, 1992: pp. 265-287.

5. Henderson RF, Harkema JR, Hotchkiss JA, Boehme DS Effect of blood leucocyte depletion on the inflammatory response of the lung to quartz. Toxicol Appl Pharmacol 1991; 109: 127-136.

6. Bansal SK, Kaw JL. Lactate dehydrogenase isoenzymes in macrophages and serum during the development of pulmonary silicosis in the rat. Toxicol Lett 1981; 7: 279-283.

7. Henderson RF, Driscoll KE, Harkema JR, et al. A comparison of the inflammatory response of the lung to inhaled versus instilled particels in F344 rats. Fund Appl Toxicol 1995; 24: 183-197.

8. DeNicola DB, Rebar AH, Henderson RF. Early damage indicators in the lung. V. Biochemical and Cytological Response to $\mathrm{NO}_{2}$ Inhalation. Toxicol Appl Pharmacol 1981; 60: 301-312.

9. Hagadorn JE, Bloor CM, Yang MS. Elevated plasma activity of lactate dehydrogenase isoenzyme-3 $\left(\mathrm{LDH}_{3}\right)$ in experimentally-induced immunologic lung injury. $\mathrm{Am} \mathrm{J}$ Pathol 1971; 64: 575-584.

10. Matusiewicz SP, Williamson IJ, Sime PJ, et al. Plasma lactate dehydrogenase: a marker of disease activity in cryptogenic fibrosing alveolitis and extrinsic allergic alveolitis? Eur Respir J 1993; 6: 1282-1286.

11. Hoffman RM, Rogers RM. Serum and lavage lactate dehydrogenase isoenzymes in pulmonary alveolar proteinosis. Am Rev Respir Dis 1991; 143: 42-46.

12. Driscoll KE, Maurer JK, Lindenschmidt RC, et al Respiratory tract responses to dust: relationships between dust burden, lung injury, alveolar macrophage fibronectin release, and the development of pulmonary fibrosis. Toxicol Appl Pharmacol 1990; 106: 88-101.

13. Roth RA. Effect of pneumotoxicants on lactate dehydrogenase activity in airways of rats. Toxicol Appl Pharmacol 1981; 57: 69-78.

14. Schultze AE, Gunaga KP, Wagner JG, et al. Lactate dehydrogenase activity and isoenzyme patterns in tissues and bronchoalveolar lavage fluid from rats treated with monocrotaline pyrrole. Toxicol Appl Pharmacol 1994; 126: 301-130.

15. The BAL Co-operative Group Steering Committee. Bronchoalveolar lavage fluid and venous blood constituents, in healthy individuals, in idiopathic pulmonary fibrosis and selected comparison groups. Am Rev Respir Dis 1990: 14: S169-202.

16. Drent M, Mulder PGH, Wagenaar SjSc, et al. Differences in BAL fluid variables in interstitial lung diseases evaluated by discriminant analysis. Eur Respir J 1993; 6: 803-810.

17. Carré PC, Mortenson RL, King TE, et al. Increased expression of the interleukin- 8 gene by alveolar macrophages in idiopathic pulmonary fibrosis: a potential mechanism for the recruitment and activation of neutrophils in lung fibrosis. J Clin Invest 1991; 88: 1802-1810.

18. Lynch III JP, Standiford TJ, Rolfe MW, et al. Neutrophilic alveolitis in idiopathic pulmonary fibrosis: the role of interleukin-8. Am Rev Respir Dis 1992; 145: 1433-1439.

19. Dunnill MS. Pulmonary fibrosis. Histopathology 1990; 16: 321-329.

20. Cherniack RM, Colby ThV, Flint A, et al. Correlation of structure and function in idiopathic pulmonary fibrosis. Am J Respir Crit Care Med 1995; 151: 1180-1188.

21. Henderson RF, Damon EG, Henderson TR. Early damage indicators in the lung. I. Lactate dehydrogenase activity in the airways. Toxicol Appl Pharmacol 1978; 44: 291-297.

22. Janssen YMW, Marsh JP, Absher MP, et al. Expression of antioxidant enzymes in rat lungs after inhalation of asbestos or silica. J Biol Chem 1992; 267: 10625-10630.

23. Vijeyaratnam GS, Corrin B. Pulmonary histiocytosis simulating desquamative interstitial pneumonia in rats receiving oral iprindole. J Path 1972; 108: 105-113.

24. Henderson RF, Scott GG, Waide JJ. Source of alkaline phosphatase activity in epithelial lining fluid of normal and injured F344 rat lungs. Toxicol Appl Pharmacol 1995; 134: $170-174$

25. Beckman Instruments Inc. Lactate dehydrogenase and iso-enzymes. Synchron CX Systems Chemistry Information, 1993.

26. DeNicola DB, Rebar AH, Henderson RF. Early damage indicators in the lung. V. Biochemical and cytological response to $\mathrm{NO}_{2}$ inhalation. Toxicol Appl Pharmacol 1981; 60: 301-312.

27. Hayes JA, Snider GL, Palmer KC. The evolution of biochemical damage in the rat lung after acute cadmiun exposure. Am Rev Respir Dis 1976; 113: 121-130.

28. Henderson RF. Use of bronchoalveolar lavage to detect lung damage. Environ Health Perspect 1984; 56: 115-129.

29. Panus PC, Matalon S, Freeman BA. Responses of type II pneumocyte antioxidant enzymes to normoxic and hyperoxic culture. In Vitro Cell Dev Biol 1989; 25: 821-829.

30. Drent M, Velzen-Blad van H, Diamant M, Wagenaar SjSc, Hoogsteden HC, Bosch van den JMM. Bronchoalveolar lavage in extrinsic allergic alveolitis: effect of time elapsed since antigen exposure. Eur Respir J 1993; 6: 1276-1281.

31. Henderson RF, Rebar AH, Pickrell JA, Newton GJ. Early damage indicators in the lung. III. Biochemical and cytological response of the lung to inhaled metal salts. Toxicol Appl Pharmacol 1979; 50: 123-136. 
32. Henderson RF, Rebar AH, DeNicola DB. Early damage indicators in the lungs. IV. Biochemical and cytologic response of the lung to lavage with metal salts. Toxicol Appl Pharmacol 1979; 51: 129-135.

33. Smith RL, Ripps CS, Lewis ML. Elevated lactate dehydrogenase values in patients with Pneumocystis carinii pneumonia. Chest 1988; 93: 987-992.

34. Fernandez P, Torres A, Miro JM, et al. Prognostic factors influencing the outcome in Pneumocystis carinii pneumonia in patients with AIDS. Thorax 1995; 50: 668-671.

35. Quist J, Hill AR. Serum lactate dehydrogenase (LDH) in Pneumocystis carinii pneumonia, tuberculosis and bacterial pneumonia. Chest 1995; 108: 415-418.

36. Chastre J, Brun P, Soler P, et al. Acute and latent pneumonitis after subcutaneous injections of silicone in transsexual men. Am Rev Respir Dis 1987: 135: 236-240.

37. DeRemee RA. Serum lactic dehydrogenase activity and diffuse interstitial pneumonitis. JAMA 1986; 204: 103-105.

38. Krugten van M, Cobben NAM, Lamers RJS, et al. Serum LDH: a marker of disease activity and its response to therapy in idiopathic pulmonary fibrosis. Neth $\mathrm{J}$ Med 1996; 48: 220-223.

39. Lindy S, Kahanpää K, Karhunen P, Halme J, Uitto J. Lactate dehydrogenase isoenzymes during the development of experimental fibrosis. J Lab Clin Med 1970; 76: 756-760.

40. Kuhn C. Cytochemistry of pulmonary alveolar epithelial cells. Am J Pathol 1968; 53: 809.

41. Evans MJ, Cabral LJ, Stephans RJ, Freeman C. Transformation of alveolar type II to type I cells following exposure to $\mathrm{NO}_{2}$. Exp Mol Pathol 1975; 22: 142-150.

42. Papadopoulos NM, Kintzios JA. Quantitative electrophoretic determination of lactate dehydrogenase isoenzymes. Am J Clin Pathol 1967; 47: 96-100.

43. Ringior SMG. Serum lactate dehydrogenase isoenzymes in human lung homotransplantation. Clin Chim Acta 1975; 58: 291-294.

44. Cabello B, Lubin J, Rywlin AM, Frenkel R. Significance of a sixth lactate dehydrogenase isoenzyme $\left(\mathrm{LDH}_{6}\right) . \mathrm{Am}$ J Clin Pathol 1980; 73: 253-258.

45. Ketchum CH, Robinson CA, Hall LM, et al. Clinical significance and partial biochemical characterization of lactate dehydrogenase isoenzyme 6. Clin Chem 1984; 30: $46-49$.
46. Onorate VA, Manly KF, Vladutiu AO. Association of an oxygen-sensitive lactate dehydrogenase isoenzyme $\mathrm{LD \kappa}$, with LD-6 in serum of critically ill patients. Clin Chem 1984; 30: 1603-1606.

47. Wolf PL. Lactate dehydrogenase-6: a biochemical sign of serious hepatic circulatory disturbance. Arch Intern Med 1985; 145: 1396-1397.

48. Valeyre D, Saumon G, Georges R, et al. The relationship between disease duration and noninvasive pulmonary explorations in sarcoidosis with erythema nodosum. Am Rev Respir Dis 1984; 129: 938-943.

49. Beck BD, Gerson B, Feldman HA, Brain JD. Lactate dehydrogenase isoenzymes in hamster lung lavage fluid after lung injury. Toxicol Appl Pharmacol 1983; 71: 59-71.

50. Romero S, Candela A, Martin C, Hernandez L, Trigo C, Gil J. Evaluation of different criteria for separation of pleural transudates from exudates. Chest 1993; 104: 399-404.

51. Roth BJ, O'Meara TF, Cragun WH. The serum-effusion albumin gradient in the evaluation of pleural effusions. Chest 1990; 98: 546-549.

52. Miloslav M, Statny B, Melinova L, Svandova E, Light RW. Diagnosis of pleural effusions: experience with clinical studies, 1986-1990. Chest 1995; 107: 1598-1603.

53. Heffner JE, Brown LK, Barbieri C, DeLeo JM. Pleural fluid chemical analysis in parapneumonic effusions: a meta-analysis. Am J Respir Crit Care Med 1995; 151: $1700-1708$.

54. Light R, Macgregor MI, Luchsinger PC, Ball WC. Pleural effusions: the diagnostic separation of transudates and exudates. Ann Intern Med 1972; 77: 507-513.

55. Black LF. Review: the pleural space and pleural fluid. Mayo Clin Proc 1972; 47: 493-505.

56. Storey DD, Dines DE, Coles DT. Pleural effusion: a diagnostic dilemma. JAMA 1976; 236: 2183-2186.

57. Light RW, Ball WC. Lactate dehydrogenase isoenzymes in pleural effusions. Am Rev Resp Dis 1973; 108: 660-664.

58. Richterich R, Burger A. Lactic dehydrogenase isoenzymes in human cancer cells and malignant effusions. Enzymol Biol Clin 1963; 3: 65-72.

59. Vergnon JM, Guidollet J, Gateau O, et al. Lactic dehydrogenase isoenzyme electrophoretic patterns in the diagnosis of pleural effusion. Cancer 1984; 54: 507-511.

60. Dev D, Joseph J, Smith MJ. Pleural lactic dehydrogenase (LD) and isoenzymes as additional diagnostic markers in pleural effusion. Thorax 1994; 474P (Abstract). 